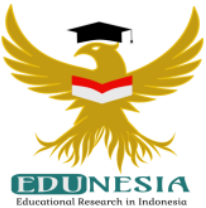

\title{
Pengembangan Modul Pembelajaran Bahasa Inggris Berbasis Andragogi Pada Program Studi Pendidikan Biologi di Universitas Muhammadiyah Palembang
}

\author{
Winda Lestari \\ Administrasi Pendidikan, Universitas Muhammadiyah Palembang, Indonesia \\ Corresponden Email: windaump@yahoo.com, Phone Number : 0895 xxxx xxxx
}

Article History:

Received: Dec 01, 2020

Revised: Dec 02, 2020

Accepted: Dec 02, 2020

Published: Jan 01, 2021

Keywords:

Teaching module based on andragogy

Kata Kunci:

Modul pembelajaran

berbasis andragogi.

\section{How to cite:}

Lestari, W. (2021) Pengembangan Modul Pembelajaran Bahasa Inggris Berbasis Andragogi Pada Program Studi Pendidikan Biologi di Universitas Muhammadiyah Palembang. Edunesia: Jurnal Ilmiah Pendidikan, 2 (1): 171-177.

This is an open access article under the $C C-B Y-N C-N D$ license (c) $(1)(5)$
Abstract: This study aims to produce an andragogy-based English module that is valid, practical and has a potential effect on student learning outcomes in semester 2 of Muhammadiyah University of Palembang. The research procedure used the Rowntree model, namely: planning, development, and evaluation. In the evaluation stage, Tessmer's formative evaluation model is used which consists of 5 stages, namely: self evaluation, expert review, one-to-one evaluation, small group evaluation, and field test. The result of this research is an andragogy-based English module. Modules are declared valid after being validated by material, language, and module design experts. The results of the one-to-one evaluation of 3 students stated that the students who were the research subjects gave very good responses to the andragogy-based module. The module is declared practical based on the results of one-to-one evaluations and small group evaluations. The results of the small group evaluation of 8 students obtained an average value of student responses to all aspects assessed at 82.47 in the practical category. The module is stated to have a potential effect on student learning outcomes because at the field test stage for 31 students, an N-gain of 0.58 was obtained, including the moderate category. Suggestions for lecturers, students and universities that this andragogy-based module can be used in learning English as well as for other researchers this andragogy-based module can be used as a reference in developing similar research.

Abstrak: Penelitian ini bertujuan untuk menghasilkan modul bahasa Inggris berbasis andragogi yang valid, praktis dan memiliki efek potensial terhadap hasil belajar mahasiswa di semester 2 Universitas Muhammadiyah Palembang. Prosedur penelitian menggunakan model Rowntree, yaitu: perencanaan, pengembangan, dan evaluasi. Pada tahap evaluasi digunakan model evaluasi formatif Tessmer yang terdiri dari 5 tahap, yaitu: self evaluation, expert review, one-to-one evaluation, small group evaluation, dan field test. Hasil penelitian ini adalah modul bahasa Inggris berbasis andragogi. Modul dinyatakan valid setelah divaliadasi oleh ahli materi, bahasa, dan desain modul. Hasil one-to-one evaluation terhadap 3 orang mahasiswa, menyatakan mahasiswa yang dijadikan subjek penelitian memberi respon sangat baik terhadap modul berbasis andragogi. Modul dinyatakan praktis berdasarkan hasil one-to-one evaluation dan small group evaluation. Hasil small group evaluation terhadap 8 orang mahasiswa memperoleh nilai rata-rata tanggapan mahasiswa terhadap semua aspek yang dinilai sebesar 82,47 dengan kategori praktis. Modul dinyatakan memiliki efek potensial terhadap hasil belajar mahasiswa karena pada tahap field test terhadap 31 orang mahasiswa diperoleh $\mathrm{N}$ gain 0,58 termasuk kategori sedang. Saran bagi dosen, siswa dan Universitas agar modul berbasis andragogi ini dapat dimanfaatkan dalam pembelajaran bahasa Inggris dengan sebaiknya serta bagi peneliti lain modul berbasis andragogi ini dapat dijadikan acuan dalam mengembangkan penelitian yang serupa. 


\section{A. Pendahuluan}

Proses pembelajaran Bahasa Inggris tingkat perguruan tinggi terdapat konsep strategi pembelajaran yang harus diarahkan pada keefektifan mahasiswa, sedangkan peran dosen adalah sebagai motivator dan fasilitator. Peran dosen sebagai motivator artinya adalah untuk meningkatkan semangat dan pengembangan kegiatan pembelajaran. Suparjo (2013) menjelaskan bahwa partisipasi dalam proses pembelajaran adalah kemampuan peserta dalam mengikuti pembelajaran dengan saling berinterkasi, melakukan elaborasi, eksplorasi, dan konfirmasi antar sesama peserta didik atau dengan pendidik.

Pembelajaran bahasa Inggris pada jurusan non bahasa termasuk dalam pembelajaran ESP (English for Specific Purposes). Tujuan ESP adalah agar peserta didik mampu menguasi Bahasa Inggris pada bidang yang mereka pelajari. Contohnya, Mahasiswa kimia materi Bahasa Inggris yang berhubungan dengan kimia. Jika mahasiswa teknik diberikan materi bahasa Inggris yang terkait dengan teknik, atau mahasiswa perhotelan, maka mahasiswa harus menguasi Bahasa Inggris yang juga berhubungan dengan dunia perhotelan dan sebagainya (Yaumi, 2012).

Pada tingkat perguruan tinggi, penggunaan media pembelajaran sangat mendukung proses perkuliahan, dengan tujuan dapat mempermudah mahasiswa dalam memahami materi yang diberikan. Menurut Pribadi (2019) Penggunaan media sebagai sarana pembelajaran telah lama dilakukan, yaitu sejak manusia melaksanakan proses dan aktivitas belajar. Reskiah (2013) mengatakan bahwa bahan ajar yang ada sering kali tidak cocok bagi peserta didik, hal ini disebabkan karena perbedaan lingkungan sosial, geografis, budaya, dan yang paling penting adalah kemampuan awal peserta didik. Dengan demikian bahan ajar yang diberikan kepada mahasiswa harus sesuai dengan kajin dan kebutuhan mahasiswa salah satunya dengan menggunakan modul. Modul adalah satu unit program pembelajaran yang terencana dan didesain dalam bentuk printed materials guna membantu peserta didik dalam mencapai tujuan/kompetensi pada masing-masing matakuliah (Kustandi \& Darmawan 2020).

Peneliti telah melakukan observasi tentang penggunaan modul sebagai bahan ajar di program studi pendidikan Biologi Universitas Muhammadiyah Palembang, beberapa dosen bahasa Inggris yang mengajar di FKIP Biologi membuat modul sebagai bahan ajar wajib digunakan mahasiswa selama proses perkuliahan, namun modul ini belum memenuhi persyaratan sebagai fasilitas pembelajaran mandiri, isi modul tidak menjelaskan materi secara terinci dan lebih jelas, sehingga mahasiswa kesulitan dalam pemahaman isi materi dan masih sangat membutuhkan penjelasan dosen untuk memahami materi tersebut. Hal ini dapat terlihat dari hasil persentasi angket yang diberikan kepada mahasiswa, angket berupa beberapa pertanyaan tentang keefektivan modul dalam pembelajaran mandiri. Dari hasil angket dapat terlihat bahwa $75 \%$ dari $100 \%$ mahasiswa masih membutuhkan penjelasan dosen tentang isi materi modul, dengan demikian modul yang telah diberikan belum termasuk dalam kategori pembelajaran mandiri, karena seperti pada pernyataan diatas bahwa modul merupakan bahan ajar yang bersifat mandiri. Selain itu, pada jurusan pendidikan Biologi, matakuliah Bahasa Inggris hanya mendapat 2 sks dalam setiap minggunya, untuk itu modul yang baik seharusnya dapat menyesuaikan keefisienan waktu, serta mengedepankan pemahaman materi yang lebih jelas sehingga mahasiswa dapat memahami isi materi secara mandiri.

Modul yang digunakan untuk matakuliah bahasa Inggris di Program Studi Pendidikan Biologi Universitas Muhammadiyah Palembang masih menggunakan 
pendekatan kepada dosen, yang mana sistem pembelajaran lebih berorientasi kepada dosen (teacher oriented). Untuk itu, modul yang akan dirancang berbasis andragogy atau pembelajaran orang dewasa. Pembelajaran orang dewasa akan berhasil dengan baik jika melibatkan baik fisik maupun mental emosionalnya. Bagi orang dewasa, investasi waktu dalam suatu kegiatan sama pentingnya dengan keputusan untuk menanam modal atau berusaha. Sejatinya pendidikan orang dewasa dapat mengakomodir segala aspek yang dibutuhkan orang dewasa yang terkait dalam aktivitas pembelajaran. Karena itu, idealnya dalam pendidikan orang dewasa dapat dilaksanakan langkah-langkah pembelajaran sebagai berikut: a. Menciptakan iklim belajar yang cocok untuk orang dewasa; b. Menciptakan struktur organisasi untuk perencanaan yang bersifat partisipatif; c. Mendiagnosis kebutuhan belajar; d. Merumuskan tujuan belajar; e. Mengembangkan rancangan kegiatan belajar; $f$. Melaksanakan kegiatan belajar; g. Mendiagnosis kembali kebutuhan belajar (evaluasi) (Zainudin, 2012). Untuk itu, modul yang akan dikembangkan akan berorientasi kepada pembelajaran mandiri dengan pendekatan sistem pembelajaran orang dewasa atau andragogi.

Rumusan masalah dalam penelitian ini adalah bagaimana modul matakuliah bahasa Inggris berbasis andragogi pada program studi pendidikan Biologi yang teruji validitasnya, praktikalitasnya, dan bagaimana efek potensial dari modul matakuliah bahasa Inggris berbasis andragogi pada program studi pendidikan Biologi yang telah dikembangkan terhadap hasil belajar mahasiswa. Sedangkan tujuan dari penelitian ini adalah menghasilkan modul bahasa Inggris berbasis andragogi pada program studi pendidikan Biologi yang teruji validitas dan praktikalitasnya serta mengetahui efek potensial dari modul tersebut.

\section{B. Metode}

Penelitian ini dilakukan di Fakultas Keguruan dan Ilmu Pendidikan (FKIP) Universitas Muhammadiyah Palembang. Subjek penelitian adalah mahasiswa semester II. Metode penelitian yang digunakan adalah penelitian pengembangan atau Development Research. Sugiono (2010) metode penelitian dan pengembangan adalah metode yang digunakan untuk menghasilkan produk tertentu, dan menguji keefektifan produk tersebut. Prosedur penelitian ini adalah penelitian pengembangan (development research) dengan menggunakan model pengembangan Rowntree. Menurut Prawiradilaga (2015) model Rowntree berisi 3 fase tahapan, yaitu tahapan perencanaan, tahapan pengembangan dan tahapan evaluasi atau penilaian. Pada tahap evaluasi, peneliti menggunakan model evaluasi formatif Tessmer yang terdiri dari tahap self-evaluation, expert review, one-to-one evaluation, small group evaluation dan field test karena evaluasi formatif oleh Tessmer dianggap cocok untuk melihat sebuah produk itu valid, praktis dan memiliki efektivitas terhadap hasil belajar mahasiswa.

Teknik pengumpulan data yang dilakukan dalam penelitian ini yaitu melalui walkthrough yang merupakan validasi data yang melibatkan beberapa ahli untuk keperluan pengecekan atau pembanding sebagai dasar untuk merevisi produk awal. Wawancara yang dilakukan kepada teman sejawat, mahasiswa dan para pakar dalam kegiatan validasi modul. Wawancara dilakukan untuk menggali permasalahan dalam pembelajaran bahasa Inggris pada jurusan non bahasa. Analisis data angket, yaitu untuk menilai kepraktikalitasan modul berbasis andragogi diberikan kepada small group 8 orang mahasiswa. Observasi digunakan untuk memperoleh data aktivitas mahasiswa dan dosen (aspek afektif) yaitu sikap kerja dalam kegiatan pembelajaran saat field test. Pemberian test 
untuk mengetahui efek potensial modul bahasa Inggris berbasis Andragogi terhadap hasil belajar mahasiswa pendidikan Biologi di FKIP Universitas Muhammadiyah Palembang. Selanjutnya teknik Analisis data.

Selanjutnya mendeskripsikan keefektifan penggunaan modul Bahasa Inggris berbasis andragogi dinyatakan efektif atau mempunyai efek potensial positif, jika hasil belajar mahasiswa (pretest dan posttest) tuntas secara klasikal.

\section{Hasil dan Pembahasan}

Pada tahap perencanaan dapat dihasilkan bahwa pada analisis kebutuhan dari hasil wawancara diperoleh bahwa mahasiswa membutuhkan modul berbasis andragogi, karena dengan menggunakan pendekatan yang berbasis andragogi atau pembelajaran orang dewasa dapat membantu mahasiswa dalam pembelajaran secara mandiri. Kemudian berdasarkan hasil analisis materi pelajaran dapat diketahu bahwa materi yang diajarkan sudah sesuai dengan capaian pembelajaran mahasiswa, namun dalam kegiatan proses pembelajaran masih terlihat peran dosen yang lebih aktif dibandingkan dengan mahasiswa atau masih bersifat teacher centered. Pada analisis karakteristik mahasiswa dapat diketahui bahwa hasil belajar mahasiswa berada pada tingkat sedang.

Tahap pengembangan desain bahan ajar yang dibuat bertujuan untuk meningkatkan daya pikir atau nalar mahasiswa dalam membahas materi bahasa Inggris. Proses pembelajarn modul berbasis andragogi ini juga dilengkapi dengan SAP sebagai skenario pembelajaran yang dilakukan. Berikut beberapa gambaran desain dari modul yang telah dibuat,
Peta Panduan awal modul yang ditulis agar mahasiswa memahami langkah pembelajaran modul tersebut.

Guideline yang diberikan agar mahasiswa memahami apa yang harus dilakukan dalam setiap komponen pembelajaran bahasa Inggris (Listening, reading, speaking dan writing)

Salah satu bentuk materi yang diberikan dalam modul tersebut.
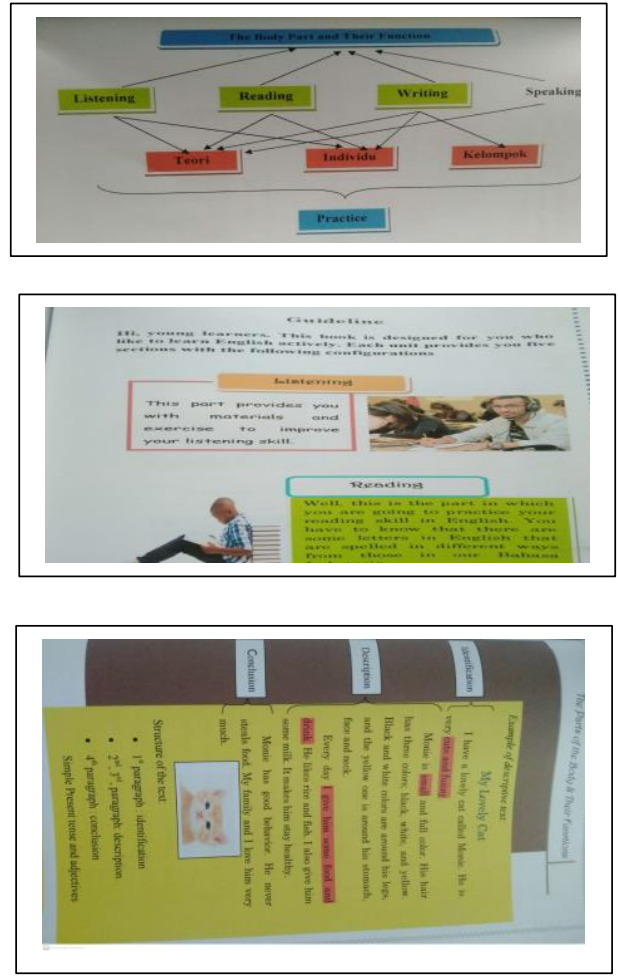

Gambar 1. Desain Modul 
Pada tahap evaluasi didapatkan hasil self-evaluation dan hasil expert review bahwa ada beberapa perbedaan tampilan antara modul bahasa Inggris berbasis andragogi sebelum diperbaiki dengan setelah diperbaiki berdasarkan saran dan kritik dari ahli (expert review). Untuk hasil one-to-one evaluation dapat disimpulkan bahwa modul bahasa Inggris berbasis andragogi yang peneliti kembangkan sudah praktis walupun masih harus dilakukan perbaikan (revisi). Hasil small group evaluation diperoleh rata-rata hasil kuesioner tanggapan mahasiswa terhadap penggunaan modul bahasa Inggris berbasis andragogi pada materi the body part and their function untuk masing-masing indikator pada tahap small group evaluation sebesar $82,47 \%$. Maka dapat disimpulkan bahwa modul bahasa Inggris berbasis andragogi ini termasuk ke dalam kategori praktis digunakan. Pada hasil field test dapat dilihat pada table dibawah ini.

Tabel 1. Hasil Obesrvasi Aktifitas mahasiswa pada Fieldtest

\begin{tabular}{cccc}
\hline $\begin{array}{c}\text { Interval } \\
\text { Skor }\end{array}$ & $\begin{array}{c}\text { Jumlah } \\
\text { siswa }\end{array}$ & Persentase & Kategori \\
\hline $42-50$ & 10 & $32.25 \%$ & Sangat Aktif \\
\hline $34-41$ & 21 & $67.75 \%$ & Aktif \\
\hline $26-33$ & 0 & $0 \%$ & Cukup Aktif \\
\hline $18-25$ & 0 & $0 \%$ & Kurang Aktif \\
\hline $10-17$ & 0 & $0 \%$ & Sangat Tidak Aktif \\
\hline Jumlah & 31 & $100 \%$ & Aktif \\
\hline Rata-rata & & 40.28 & \\
\hline
\end{tabular}

Berdasarkan hasil obeservasi pada fieldtest diperoleh angka rata-rata keaktifan mahasiswa sebesar 40,28 dan dikategorikan aktif. Berdasarkan dari tahapan-tahapan yang dilakukan oleh peneliti untuk mencapai tujuan dari penelitian ini, maka dapat disimpulkam bahwa modul pembelajaran bahasa Inggris berbasis andragogi dinyatakan valid, praktis, dan memiliki efek potensial terhadap hasil belajar mahasiswa. Modul pembelajaran bahasa Inggris dengan pendekatan andragogi ini dapat meningkatkan hasil belajar mahasiswa karena dengan menggunakan modul ini mahasiswa dapat belajar secara mandiri dan didorong untuk memanfaatkan sumber-sumber belajar di sekitarnya secara mandiri. Modul pembelajaran bahasa Inggris berbasis andragogi memiliki beberapa konsep, adapun konsep diri merupakan konsep paling menonjol dalam pengembangan modul pembelajaran bahasa Inggris, yang mana secara umum konsep diri anak-anak masih tergantung sedangkan pada orang dewasa konsep dirinya sudah mandiri.

Adapun kelebihan yang terdapat dalam modul pembelajaran bahasa Inggris berbasis andragogi, yaitu:

1. Modul pembelajaran bahasa Inggris dilengkapi dengan CD listening yang mempermudah mahasiswa dalam memahami bacaan dan cara membaca kata-kata.

2. Modul pembelajaran bahasa Inggris berbasis andragogy dilengkapi dengan gambargambar yang dapat mempermudah mahasiswa memahami isi materi yang diberikan.

Sedangkan kelemahan dari modul pembelajaran bahasa Inggris berbasis andragogi ada pada keterbatasan waktu selama proses pembelajaran dikelas, karena mahasiswa biologi semester 2 hanya memiliki 2 sks perminggunya untuk matakuliah bahasa Inggris. Berdasarkan kelebihan dan kekurangan dalam pengembangan modul pembelajaran 
tesebut diharapkan dapat digunakan sebagai acuan bagi pengembang lain untuk mengembangkan modul pembelajaran lainnya.

Hal ini dapat dibandingkan dengan hasil penelitian sebelumnya, yang mana hasil penelitian yang dilakukan oleh Yusnita (2009) dengan penelitian yang berjudul "Pengembangan Modul Kewarganegaraan pada Program Studi Ilmu Keperawatan Sekolah Tinggi Ilmu Kesehatan (STIK) Bina Husada Palembang". Hasil penelitian ini menyatakan bahwa pengembangan modul sudah valid, telah praktis, mudah digunakan, dan bermafaat, serta penggunaan modul kewarganegaraan dapat dilaksanakan dengan hasil yang efektif.

Selanjutnya, hasil penelitian yang dilakukan oleh Peniati (2012) pada program studi Pendidikan IPA, fakultas matematika dan ilmu pengetahuan alam di Universitas Negeri Semarang. Penelitian tersebut yang berjudul "pengembangan modul mata kuliah strategi belajar mengajar IPA berbasis hasil penelitian pembelajaran" menjelaskan bahwa, berdasarkan hasil penelitian dapat disimpulkan, pengembangan modul yang dilakukan dinilai layak oleh pakar untuk digunakan dalam pembelajaran serta efektif digunakan dalam pembelajaran berdasarkan penelitian keefektifan dari perolehan nilai akhir mahasiswa.

\section{D. kesimpulan}

Berdasarkan hasil penelitian yang telah dilakukan tentang pengembangan modul bahasa Inggris dengan tema the body part and their function berbasis andragogi untuk mahasiswa semester 2 jurusan Fakultas Keguruan dan Ilmu Pendidikan (FKIP) Biologi di Universitas Muhammadiyah Palembang dapat disimpulkan sebagai berikut:

1. Modul bahasa Inggris dengan tema the body part and their function berbasis andragogi dinyatakan valid oleh para ahli materi, ahli desain, dan ahli media. Sehingga layak digunakan dalam pembelajaran bahasa Inggris untuk mahasiswa jurusan non bahasa Inggris.

2. Modul bahasa Inggris dengan tema the body part and their function berbasis andragogi dinyatakan praktis setelah diujicobakan kepada mahasiswa dengan melakukan one to one terhadap tiga orang mahasiswa dengan kemampuan yang berbeda melalui teknik wawancara. Sehingga dapat dinyatakan modul tersebut layak digunakan dalam pembelajaran bahasa Inggris untuk mahasiswa non bahasa Inggris.

3. Dari hasil analisi tes (pretest dan posttest) pada tahap fieldtest diperoleh ketuntasan hasil belajar sebesar $81.22 \%$. Dengan demikian menunjukkan bahwa modul bahasa Inggris dengan tema the body part and their function berbasis andragogi mempunyai efek potensial yang positif terhadap hasil belajar mahasiswa.

Adapun saran atas kesimpulan diatas dapat diberikan saran bagi dosen, diharapkan dapat menggunakan modul berbasis andragogi sebagai bahan pembelajaran alternatif dalam mengefektifkan proses pembelajaran sehingga diharapkan dapat meningkatkan hasil belajar mahasiswa Fakultas Keguruan dan Ilmu Pendidikan (FKIP) di Universitas Muhammadiyah Palembang. Bagi mahasiswa, diharapkan modul berbasis andragogi yang dihasilkan dapat bermanfaat bagi mahasiswa sebagai sarana untuk mecapai hasil optimal dalam proses pembelajaran bahasa Inggris. Bagi Universitas, dapat memberikan sumbagan pengetahuan dalam rangka meningkatkan keefektivitas pembelajaran sehingga dapat mendorong peningkatan hasil belajar bahasa Inggris. Bagi peneliti lain, diharapkan dapat melakukan penelitian lanjutan tentang modul pembelajaran bahasa Inggris berbasis andragogi. 


\section{Daftar Pustaka}

Arif, Z. (2012). Andragogi. Bandung: Angkasa Bandung.

Peniati, P.E. (2012). Pengembangan Modul Mata Kuliah Startegi Belajar Mengajar Berbasis Hasil Penelitian Pembelajaran. Jurnal Pendidikan IPA Indonesia, 1 (1), 8-15

Prawiradilaga, D. S. (2015). Prinsip Desain Pembelajaran (Instructional Design Principles). Jakarta: Kencana Prenada Media Group.

Pribadi, A.B. (2019). Media dan Teknologi dalam Pembelajaran. Jakarta: Prenadamedia Group.

Kustandi, C., \& Darmawan, D. (2020). Pengembangan Media Pembelajaran. Jakarta: Kencana.

Rezkiah, S., Suhery, T., \& Putri, R.I.I. (2013). Pengembangan Bahan Ajar Berbasis Berpikir Kritis Materi Hukum Newton di Sekolah Menengah Pertama. Jurnal Inovasi Pendidikan. 3, 165-182.

Sugiono. (2010). Metode Penelitian Pendidikan: Pendekatan Kualitatif, Kuantitatif dan RED. Bandung: Alfabeta.

Suparjo. (2013). Pengembangan Lembar Kerja Siswa Berbasis Problem Soving pada Kompetensi Keahlian Teknik Sepeda Motor Materi Sistem Kelistrikan untuk Sekolah Menengah Kejuruan. Jurnal Inovasi Pendidikan, 3(2). 1999-217.

Yaumi, M. (2012). Pengembangan Bahan Ajar English For Specific Purposes Berbasis TIK. Lentera Pendidikan, 15 (2). 186-218.

Yusnita, E. (2009). Pengembangan Modul Kewarganegaraan Pada Program Studi Ilmu Keperawatan Sekolah Tinggi Ilmu Kesehatan (STIK) Bina Husada Palembang. (Tesis program magister pendidikan pasca sarjana Universitas Sriwijaya, tidak dipublikasi). 